\title{
Dynamics of the population structure and genetic variability within Iranian isolates of grapevine fanleaf virus: evidence for polyphyletic origin
}

\author{
Z. GHOLAMPOUR ${ }^{1}$, M. KARGAR ${ }^{1}$, M. ZAKIAGHL ${ }^{*}$, M. SIAMPOUR ${ }^{2}$, M. MEHRVAR $^{1}$, K. IZADPANAH $^{3}$
}

\begin{abstract}
${ }^{1}$ Department of Plant Pathology, College of Agriculture, Ferdowsi University of Mashhad, Mashhad, Iran; ${ }^{2}$ Department of Plant Protection, College of Agriculture, Shahrekord University, Iran; ${ }^{3}$ Plant Virology Research Center, College of Agriculture, Shiraz University, Shiraz, Iran
\end{abstract}

Received December 1, 2016; revised December 19, 2016; accepted July 3, 2017

\begin{abstract}
Summary. - To determine the genetic diversity and population structure of grapevine fanleaf virus (GFLV), the complete nucleotide sequence of the coat protein gene of 41 isolates from different regions in Iran was determined. Phylogenetic analyses of these isolates together with those available in the GenBank revealed two evolutionary divergent lineages, designated GFLV-G and GFLV-Ir that reflect origin of the isolates. Analysis of the genetic variability in the coat protein of these isolates revealed 37 genotype groups in GFLV population. Analyses indicate that GFLV-G and GFLV-Ir clades are significantly differentiated populations of GFLV. Also, geographical subpopulations of the virus in Iran were completely distinct from each other. Examination of nonsynonymous/synonymous nucleotide diversity showed that the $\mathrm{CP}$ gene has been under purifying selection. The neutrality tests indicate balancing selection operating within isolates of the northwest of Iran and purifying selection within the other populations.
\end{abstract}

Keywords: grapevine fanleaf virus; Iran; polyphyletic; population structure

\section{Introduction}

Grapevine fanleaf virus (GFLV) is responsible for degeneration disease which is an important disease of grapevine worldwide. The first report of GFLV dates back to the 17th century (Andret-Link et al., 2004). GFLV belongs to the genus Nepovirus in the family Secoviridae within the order Picornavirlaes (Sanfacon et al., 2012). It causes significant economic losses by reducing grape yield up to $80 \%$, lowering fruit quality and shortening the longevity of the vines (Andret-Link et al., 2004). In nature, the virus invades all grapevine cultivars and some herbaceous plants including bermudagrass, knotweed and raspberry shrub (Izadpanah et al., 2003a,b).

GFLV genome is composed of two single stranded positive-sense RNA of approximately $7.3 \mathrm{~kb}$ and $3.7 \mathrm{~kb}$,

*Corresponding author: E-mail: zakiaghl@ferdowsi.um.ac.ir; phone: +98-511-8795620.

Abbreviations: $\mathrm{CP}=$ coat protein; $\mathrm{GFLV}=$ grapevine fanleaf virus; RFLP $=$ restriction fragment length polymorphism encapsidated into a small icosahedral particle. The genome contains viral protein genome-linked (VPg) and a poly(A) tail at its $5^{\prime}$ and $3^{\prime}$ ends, respectively (Andret-Link et al., 2004). Each genomic RNA encodes a polyprotein which releases functional proteins after proteolytic cleavages with viral-encoded protease. RNA1 encodes proteins involved in replication, whereas RNA2 codes for a homing protein (required for RNA2 replication), a movement protein and a coat protein (CP) (Vigne et al., 2009). Also, a large satellite RNA molecule, encoding a $37 \mathrm{kDa}$ protein, is found to be in association with some GFLV isolates (Pinck et al., 1988).

GFLV induces fanleaf, yellow mosaic and vein banding syndromes in infected grapevine (Andret-Link et al., 2004). Alteration of symptoms in $N$. benthamiana is related to the variation of RNA dependent RNA polymerase (RdRp) gene of GFLV (Vigne et al., 2013). GFLV is spread by its specific nematode vector, Xiphinema index, and also by infected planting material (Andret-Link et al., 2004).

The genetic variability of the GFLV genome has been investigated using different methods including restriction fragment length polymorphism (RFLP), single-strand 
conformation polymorphism analysis (SSCP) (Nolasco and Sequeira 1993), and sequence analysis of the CP gene from several isolates from Europe, America, Africa and Asia in conventional or transgenic grapevines (Fattouch et al., 2005; Naraghi-Arani et al., 2001; Serghini et al., 1990; Vigne et al., 2009).

Sequence analysis has revealed a high level of genetic variation within the genome of GFLV populations, suggesting that the virus consists of genetically diverse variants in a quasispecies population (Naraghi-Arani et al., 2001; Schneider and Roossinck, 2000).

It has been proposed that GFLV has been originated from ancient Persia (now Iran) and spread to its current worldwide distribution via infected plant materials (Vuittenez, 1970). Iran is a vast country located between two longitudes. Vineyards are scattered all over Iran on about 273,000 ha with $\sim 2.75$ million tons of annual grape production. Field observations had revealed a variety of GFLV-like symptoms in vineyards from different regions of this country. The genetic diversity of the Iranian isolates of GFLV had been studied by targeting the homing protein (Nourinejhad Zarghani et al., 2013), movement protein (Bashir et al., 2007a) and CP genes (Bashir et al., 2007b, 2011; Pourrahim et al., 2007). Phylogenetic analysis has revealed that the Iranian isolates are highly diverse and form a distinct cluster among GFLV isolates from across the world (Bashir et al., 2007a, 2011; Bashir and Melcher, 2012).

The main objective of this study was to obtain new insights on the population structure and genetic diversity of GFLV isolates from Iran that would be subsequently useful in epidemiological studies and in designing effective transgenic approaches for disease management. Our analysis focused on the CP gene sequence, for which a large amount of sequence data was available from around the world. These large sequence data together with sequence variability of the CP gene would increase the statistical power for analysis of the GFLV population diversity. In the pursuit of this objective, the CP gene sequences of 361 GFLV isolates from around the world (including 41 new isolates from Iran) were thoroughly analyzed for genotyping and phylogenetic relationships.

\section{Materials and Methods}

Virus source and serological detection of GFLV. Leaf samples were randomly collected during the growing seasons of 2012-14 from the vineyards of Sabzevar (57.40E, 36.12N), Neyshapour (58.40E, $36.12 \mathrm{~N}$ ), Kashmar (58.28E, 35.14N) and Bardaskan (58.02E, $34.44 \mathrm{~N}$ ) in Khorasan Razavi province (northeast of Iran), and Shiraz (52.32E, 29.36N), Bavanat (53.42E, 31.04N), Saadatshahr $(52.36 \mathrm{E}, 30.05 \mathrm{~N})$ and Kavar $(52.46 \mathrm{E}, 29.14 \mathrm{~N})$ in Fars province (southern Iran). Specific antibody raised against an Iranian isolate of GFLV (Zaki-Aghl and Izadpanah, 2003) was used to detect the virus in leaf extracts by indirect-ELISA as described by Converse and Martin (Converse and Martin 1990).

$R T-P C R$, cloning and sequencing. Total RNA was extracted from petioles using CTAB-PVPP method (Gibbs and Mackenzie, 1997). The first cDNA strand was synthesized using Thermoresistant MMuLV reverse transcriptase (Parstous, Iran) according to manufacturer's protocol. Two primers, GFLV-CPF (5'-GCTCAC GATCTGTGAGG-3') and GFLV-CPR (5'-ACAAACAACACACT GTCGCC-3') were designed from the conserved regions of CP gene sequences of $70 \mathrm{GFLV}$ isolates from Iran and other countries (Table 1). These primers were used for amplification of complete GFLV CP gene. PCR amplification was performed in $25 \mu \mathrm{l}$ volume of Red Ampliqon PCR master mix (Amplicon, Denmark) containing 10 pmoles of each primer and $4 \mu \mathrm{l}$ of the cDNA. The PCR thermal profile was at $95^{\circ} \mathrm{C}$ for $3 \mathrm{~min}$ followed by 35 cycles at $94^{\circ} \mathrm{C}$ for 30 s, $52^{\circ} \mathrm{C}$ for $45 \mathrm{~s}, 72^{\circ} \mathrm{C}$ for $2 \mathrm{~min}$, and terminated by $72^{\circ} \mathrm{C}$ for $5 \mathrm{~min}$. PCR products from 41 selected GFLV isolates were purified using Reaction recovery kit (Denazist Asia, Iran). Purified products were ligated into the pTZ57R/T vector using an InsT/A clone PCR product cloning kit (Thermo scientific) according to the manufacturer's instructions. Plasmids were then cloned into E. coli strain DH5a. Recombinant plasmids were purified from bacterial cells using plasmid DNA isolation kit (Denazist Asia, Iran). The clones were sequenced bi-directionally using pUC-M13 universal primers with an ABI PRISM system (Macrogen Company, South Korea).

RFLP analysis. The RT-PCR products corresponding to the CP gene of 77 Iranian GFLV isolates were subjected to RFLP analysis using TaqI restriction endonuclease (Vivantis, Malaysia). Generated fragments were separated by electrophoresis on a $2 \%$ agarose gel containing DNA Green Viewer (Parstous, Iran).

Phylogenetic analysis. Nucleotide alignment of the CP gene sequences of $361 \mathrm{GFLV}$ isolates, including 41 new GFLV isolates from northeast and southern regions of Iran (provided in this study, Table 2), together with 50 isolates from other parts of Iran and 270 isolates from other countries previously deposited in GenBank (Table 1), was generated using the MUSCLE module in MEGA v.5 (Tamura et al., 2011). Phylogenetic tree for the CP gene of GFLV isolates were reconstructed by the Minimum evolution method using MEGA v.5, with the maximum composite likelihood nucleotide substitution model. The integrity of the evolutionary relationships was assessed by 1000 bootstrap replicates. Preliminary tree was made for 361 GFLV isolates but due to space limitation to show the tree in a single page, 111 out of 361 isolates were selected based on neighbor joining clustering of isolates using SDT v.1 software and the tree was reconstructed using MEGA. Pairwise distance comparisons of the CP gene sequences were computed using TamuraNei model in MEGA v.5. The pairwise nucleotide and amino acid sequence identity scores were represented as color-coded blocks using SDT v.1 software (Muhire et al., 2013). Genotype grouping of 361 GFLV isolates was made based on the pairwise-identity scores using SDT v.1 software.

Population genetic analysis. Analyses were conducted using 361 CP gene sequences of GFLV isolates retrieved from Gen- 
Table 1. List of the GFLV genotypes

\begin{tabular}{|c|c|c|c|}
\hline Genotype & No. & Country & Acc. No. \\
\hline G1 & 26 & Iran & $\begin{array}{l}\text { FJ513386, FJ513376, JQ071377, JQ071376, AY942809, AY942808, FJ513383, JQ071376, FJ513382, FJ513381, } \\
\text { FJ513379, FJ513378, JQ071374, JQ071375, FJ513385, FJ513384, FJ513380, JQ071377, AY997693, AY997694, } \\
\text { AY997697, AY997699, AY997698, AY942807, AY942806, AY942805 }\end{array}$ \\
\hline G2 & 5 & Iran & KJ913791, KJ913795, KJ913796, KJ913798, KJ913792 \\
\hline G3 & 5 & Iran & KJ913790, KJ913794, KJ913797, KJ913799, KJ913801 \\
\hline G4 & 7 & Iran & DQ513333, DQ513332, DQ513334, DQ513335, DQ513336, KJ913800, KX418443 \\
\hline G5 & 12 & Spain, South Africa & $\begin{array}{l}\text { JN585776, JN58 } \\
\text { 5778, JN585772, JN585774, JN585773, JN585775, EU702450, EU702449, EU702448, EU702451, EU702446, } \\
\text { EU702447 }\end{array}$ \\
\hline G6 & 4 & Chile & HM636858, HM636860, HM636854, HM636853 \\
\hline G7 & 6 & Slovenia & DQ922666, DQ922667, DQ922678, DQ922671, DQ922669, DQ922664 \\
\hline G8 & 4 & Austria, USA, Iran & U11768, AF304013, KJ913793, KJ913802 \\
\hline G9 & 1 & Czech Republic & AY821657 \\
\hline G10 & 6 & Iran & AY942813, AY942812, AY942811, AY942810, AY997696, AY997695 \\
\hline G11 & 5 & France, Hungary & AY370975, AY370974, AY370976, AY371026, EF426852 \\
\hline G12 & 7 & South Africa & EU702440, EU702441, EU702443, EU702444, KC900163, EU702442, JF968121 \\
\hline G13 & 7 & $\begin{array}{l}\text { Poland, Czech Re- } \\
\text { public }\end{array}$ & KF029761, KF029760, GU062186, GU053733, GU053732, KF029759, GU053731 \\
\hline G14 & 2 & USA & GU972575, GU972571 \\
\hline G15 & & Germany, Chile & AY017338, HM636862, HM636856 \\
\hline G16 & 18 & $\begin{array}{l}\text { USA, Chile, USA, } \\
\text { Italy }\end{array}$ & $\begin{array}{l}\text { GU972576, GU972578, GU972577, KC162001.1, GU972572, GU972584, GU972573, GU972579, GU972583, } \\
\text { HM636859, GQ415403, HM636857, HM636855, KC256965, DQ362924, GQ332368, GQ332367, GQ332369 }\end{array}$ \\
\hline G17 & 5 & Chile, USA, Italy & KC256955, GQ332364, GQ332365, DQ362921 \\
\hline G18 & 27 & $\begin{array}{l}\text { Spain, France, USA, } \\
\text { South Africa, Italy }\end{array}$ & $\begin{array}{l}\text { JN585771, JN585770, JN585769, JN585768, JN585766, JN585767, AY371020, AY371018, AY370998, GQ332370, } \\
\text { KC256964, DQ362931, GU972582, GU972581, EU702445, DQ362925, AF304014, EF426829, EF426828, } \\
\text { EF426833, FJ544933, FJ544934, EF426836, EF426837, EF426840, EF426835, EF426834 }\end{array}$ \\
\hline G19 & 5 & Chile & KC256962, KC256963, JX513895, JX559643, JX513890 \\
\hline G20 & 4 & Spain, USA, Canada & JN585796, JN585794, JN585797, JN585795 \\
\hline G21 & 23 & Slovenia & $\begin{array}{l}\text { DQ922655, DQ922659, DQ922654, DQ922653, DQ922656, DQ922658, DQ922661, DQ922660, DQ922657, } \\
\text { DQ922673, DQ922672, DQ922662, DQ922675, DQ922652.1Slovenia, DQ922676, DQ922670, DQ922677, } \\
\text { DQ922674, DQ922668, DQ922665, DQ922679, DQ922663 }\end{array}$ \\
\hline G22 & 7 & France, China & AY370966, AY370951, AY370968, AY371011, AJ318415, AJ318415, AY371025 \\
\hline G23 & 2 & Italy & DQ362934, DQ362933 \\
\hline G24 & 15 & $\begin{array}{l}\text { Spain, France, Italy, } \\
\text { Chile, Iran }\end{array}$ & $\begin{array}{l}\text { JN585790, JN585792, JN585791, JN585793, AY780899, AY370956, AY780901, AY370959, AY370952, AY370987, } \\
\text { DQ362922, DQ362923, KC256961, KX418454, KX418452 }\end{array}$ \\
\hline G25 & 11 & Spain & $\begin{array}{l}\text { JN585765, JN585801, JN585798, JN585800, JN585799, JN585789, JN585783, JN585782, JN585779, JN585780, } \\
\text { JN585781 }\end{array}$ \\
\hline G26 & 17 & $\begin{array}{l}\text { France, Italy, Brazil, } \\
\text { Spain }\end{array}$ & $\begin{array}{l}\text { AY371022, AY371016, AY371004, AY371021, AY371019, AY371012, AY370993, AY370986, GU053735, } \\
\text { AY464090, AY371027, AY370997, EU258681, X60775, EF426849, EF426851, EF426850 }\end{array}$ \\
\hline G27 & 6 & Chile, Italy & DQ526452, KC256966, KC256960, KC256959, KC256954, GU053734 \\
\hline G28 & 33 & France, Italy, Iran & $\begin{array}{l}\text { AY370947, AY780902, AY370949, AY370970,AY370973, AY370977, AY370989, AY370984, AY371024, AY371000, } \\
\text { AY370999, AY371023, AY370996, AY370985, AY370961, AY370955, AY370978, AY370972, AY370950, } \\
\text { AY371006, AY371002, AY371001, AY370992, AY370960, AY370980, AY370945, AY370991, AY370990, } \\
\text { AY370963, AY370954, DQ362926, KX418457, KX418461 }\end{array}$ \\
\hline G29 & 7 & France, USA, Iran & NC 003623, GU972580, X16907, DQ672565, DQ672566, DQ672567, KX418451 \\
\hline G30 & 4 & Chile, USA, China & KC256957, KC256956, KC256958, AF304015 \\
\hline G31 & 29 & France & $\begin{array}{l}\text { AY370983, AY370982, AY371005, AY370981, AY371017, AY370967, AY370965, AY780900, AY370962, } \\
\text { AY370946, AY370979, AY370958, AY370953, AY370995, AY370994, AY370942, AY370941, AY370943, } \\
\text { AY370944, AY370971, AY371015, AY371013, AY370964, AY371003, AY370969, AY370948, AY371007, } \\
\text { AY371008, AY780903 }\end{array}$ \\
\hline G32 & 10 & $\begin{array}{l}\text { Italy, USA, Chile, } \\
\text { Spain, Tunisia }\end{array}$ & $\begin{array}{l}\text { FJ531813, GQ332371,FN555304 ENTAV115, HM636861, JN585788, JN585786, JN585787, JN585785, } \\
\text { JN585784, AY525606 }\end{array}$ \\
\hline G33 & 9 & Italy, USA, Iran & DQ362929, DQ362927, DQ362928, GU972574, DQ362932, DQ362930, AY942804, AY942803, AY942802 \\
\hline G34 & 25 & Italy, France & $\begin{array}{l}\text { DQ362920, EF426842, FJ544937, FJ544932, EF426848, EF426847, EF426845, EF426844, EF426841, } \\
\text { EF426824.1France, EF426823, EF426825, EF426826, EF426830, FJ544931, EF426832, FJ544935, FJ544936, } \\
\text { EF426827, EF426843, EF426831, FJ544939, FJ544938, EF426846, EF426838 }\end{array}$ \\
\hline G35 & 2 & Iran & KX418456, KX418450 \\
\hline G36 & 3 & Iran & KJ913789, KX418447, KX418449 \\
\hline G37 & 2 & Brazil & EU258680, EU038294 \\
\hline
\end{tabular}

Isolates used in phylogenetic study are represented in bold. 
Bank (320 isolates, Table 1) or obtained in this study (41 new Iranian isolates, Table 2). Out of GFLV CP sequences retrieved from GenBank, 50 were from Iran and the others were from other countries in the world. DnaSP version 5.10.01 (Libardo and Rozas 2009) was used for calculating the average pairwise nucleotide diversity $(\mathrm{Pi})$, number of polymorphic sites $(\mathrm{S})$, total number of mutations (eta), average number of nucleotide differences between sequences from the same population $(\mathrm{K})$, the haplotype diversity ( $\mathrm{Hd}$ ) and the ratio of non-synonymous to synonymous nucleotide diversity ( $\mathrm{dN} / \mathrm{dS})$. The nucleotide diversity measures the average pairwise variation among sequences with values ranging from 0 (no variation) to 0.1 (extreme variation). The haplotype diversity indicates the frequency of haplotypes in a sample with values ranging from 0 to 1.000 (Tsompana et al., 2005). Also, this program was used for examining Tajima's D (Tajima 1989), Fu and Li's D* and Fu and Li's $\mathrm{F}^{\star}$ (Fu and Li, 1993) tests of neutrality.

Tests of population differentiation. Four independent statistical tests of population differentiation, including $\mathrm{Kst}^{\star}, \mathrm{Z}^{\star}$, Snn and $\mathrm{F}_{\mathrm{ST}}$ were run using DnaSP program to estimate the genetic differentiation among Iranian GFLV populations. The Kst* is expected to be near zero if there is no genetic differentiation (the null hypothesis), and so the null hypothesis is rejected if $\mathrm{Kst}^{*}$ is supported by a small $P$-value (0.05) (Hudson et al., 1992a). The $\mathrm{Z}^{\star}$ statistic is a logarithmic ranking of distances between all pairs of sequences (Hudson et al., 1992b). The frequency of the nearest neighbor sequences in each location is measured by the Snn test statistic (Hudson 2000), of which value is 1 when populations from different localities are genetically distinct or 0.5 in the case of panmixia. $\mathrm{F}_{\mathrm{ST}}$ is the coefficient of gene differentiation or fixation index and measures interpopulation diversity. It has a value range between 0.0 , indicating no differentiation between the populations, to a maximum of 1.0 indicating the populations are completely differentiated (Hudson et al., 1992b). Statistical significances for all tests were established using 1000 permutations.

\section{Results}

\section{Prevalence of GFLV in Iran}

The prevalence of GFLV in Iran was assessed by detection of the virus in plants sampled from vineyards in eight regions from the north-east and south of Iran. Out of 738 plants tested, GFLV was detected by ELISA in samples collected from all regions with the incidence as follows: Sabzevar (21/91; infected/total), Neyshabur (8/20), Kashmar (51/67), Bardaskan (34/56), Shiraz (64/143), Bavanat (97/136), Saadatshahr (8/47) and Kavar (5/17). Kashmar, in the northeast and Bavanat in the south of Iran, had the highest incidence of the GFLV (76 and 71\%, respectively). GFLV was detected in grapevines showing fanleaf, mosaic, yellowing, vein banding and shortened internode symptoms. However, many of
Table 2. List of the new Iranian GFLV isolates

\begin{tabular}{lccccc}
\hline \multirow{2}{*}{ No. } & \multicolumn{2}{c}{ Northeast of Iran } & & \multicolumn{2}{c}{ Southwest of Iran } \\
\cline { 2 - 3 } \cline { 5 - 6 } & Acc. No. & Origin & & Acc. No. & Origin \\
\hline 1 & KJ913789 & Kashmar & & KX418443 & Shiraz \\
2 & KJ913790 & Kashmar & & KX418444 & Shiraz \\
3 & KJ913791 & Kashmar & & KX418445 & Bavanat \\
4 & KJ913792 & Kashmar & & KX418446 & Bavanat \\
5 & KJ913793 & Kashmar & & KX418447 & Shiraz \\
6 & KJ913794 & Kashmar & & KX418448 & Bavanat \\
7 & KJ913795 & Kashmar & & KX418449 & Kavar \\
8 & KJ913796 & Bardaskan & & KX418450 & Saadatshahr \\
9 & KJ913797 & Bardaskan & & KX418451 & Bavanat \\
10 & KJ913798 & Bardaskan & & KX418452 & Shiraz \\
11 & KJ913799 & Sabzevar & & KX418453 & Bavanat \\
12 & KJ913800 & Sabzevar & & KX418454 & Bavanat \\
13 & KJ913801 & Sabzevar & & KX418455 & Bavanat \\
14 & KJ913802 & Neyshabour & & KX418456 & Shiraz \\
15 & KJ913803 & Mashhad & & KX418457 & Bavanat \\
16 & KJ913804 & Kashmar & & KX418458 & Bavanat \\
17 & KJ913805 & Bardaskan & & KX418459 & Bavanat \\
18 & KJ913806 & Kashmar & & KX418460 & Shiraz \\
19 & KJ913807 & Kashmar & & KX418461 & Bavanat \\
20 & KJ913808 & Mashhad & & & \\
21 & KJ913809 & Mashhad & & & \\
\hline & KJ913810 & Bardaskan & & & \\
\hline & & & & & \\
\hline
\end{tabular}

the ELISA positive samples were from asymptomatic plants (63\%, 181 out of 288 ELISA positive samples).

\section{RT-PCR and genetic variability among GFLV isolates}

Using GFLV specific primers, a 1760 bp DNA fragment was amplified in RT-PCR of 77 ELISA positive samples from different areas of Iran, but 41 out of 77 PCR products were sequenced (Table 2). All of the ELISA positive samples subjected to PCR assays yielded a product of the expected size. This confirmed the efficiency of primers used in this study for amplification of the CP gene from diverse GFLV strains. Analysis of sequencing data revealed that this fragment consisted of 15 nucleotides of the 3 ' end of movement protein, 1515 nucleotides covering the whole CP gene (corresponding to nucleotides 2048-3559 in the RNA2 of the GFLV-F13; NC003623), followed by 230 nucleotides of the 3' UTR.

Pairwise nucleotide sequence comparisons of the CP gene sequences from 41 new Iranian GFLV isolates together with those obtained from GenBank $(n=320)$ (Table 1$)$ revealed a global similarity between 82.2 and $100 \%$. The average CP sequence distance among all GFLV isolates was $11.02 \pm 2.36 \%$ and $4.79 \pm 1.72 \%$ at the nucleotide and amino acid levels, respectively. The average divergence among the Iranian isolates was $9.18 \pm 3.21 \%$ and $7.44 \pm 2.29 \%$ at the nucleotide and amino acid levels, respectively. 


\section{RFLP analysis of GFLV populations}

The population structure of 77 GFLV isolates from vineyards in the northeast and south of Iran was investigated by PCR-RFLP analysis of the CP gene (1760 bp as described above) using TaqI. Most of the GFLV isolates tested (45 out of 77; 58\%) had complex RFLP patterns (restrictotype) for which the pooled size of DNA fragments was larger than expected (Fig. 1). This revealed the presence of more than one predominant restrictotype within the population structure. It must be noted that the virtual TaqI RFLP patterns of the CP gene sequences were identical to that of actual patterns.

Comparison of RFLP results distinguished 10 and 9 distinct restrictotypes in the GFLV populations from the northeast and south of Iran, respectively (Fig. 1, Table 3). However, the frequency of restrictotypes was variable in different regions of Iran. Restrictotype R1 was found common among isolates from northeast and south of Iran; however, restrictotypes $\mathrm{R} 5, \mathrm{R} 10$ and $\mathrm{R} 11$ were predominant in the northeast of Iran and restrictotypes R3, R6 and R7 were common in the south of Iran (Fig. 1, Table 3). Most restrictotypes were found in both surveyed regions, but some of them had limited distribution (Fig. 1, Table 3).

Moreover, virtual TaqI RFLP analysis of 28 complete CP genes from GFLV isolates of northwest of Iran generated 11 distinct restrictotypes in the populations, of which 4 restrictotypes were prevalent (Fig. 1, Table 3).

\section{Phylogenetic position of GFLV populations}

A phylogenetic tree generated from the alignment of 111 GFLV CP gene sequences revealed the clustering of GFLV isolates into two evolutionary distinct lineages. These two major clades, designated as GFLV-Global (GFLV-G) and GFLV-Iran (GFLV-Ir), included 88 and 23 isolates, respectively (Fig. 2).

As shown in the phylogenetic tree Iranian GFLV isolates were distributed between the two clades. However, the majority of Iranian GFLV isolates grouped within the GFLV-Ir

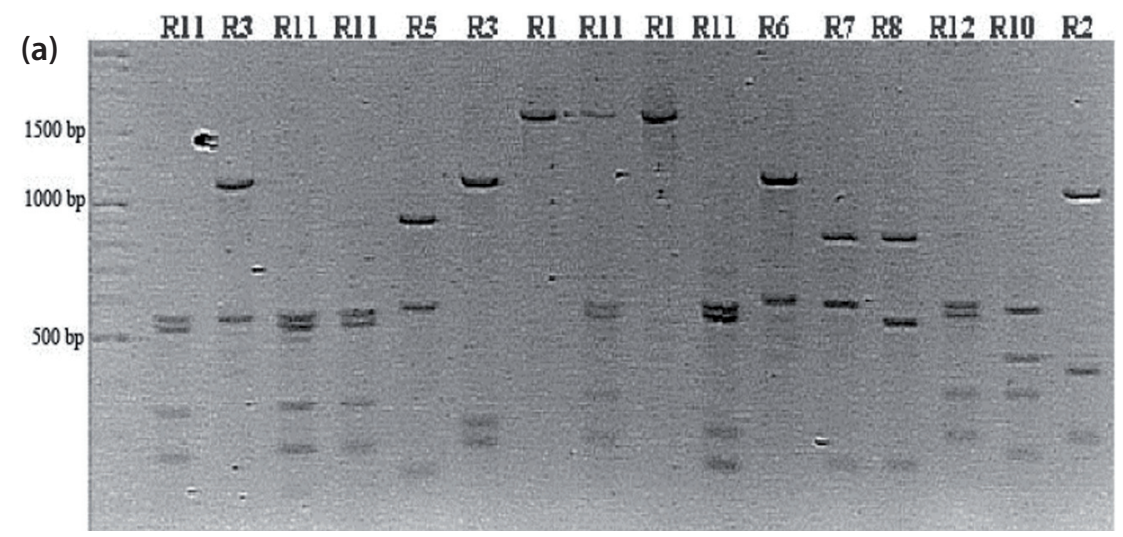

(b)

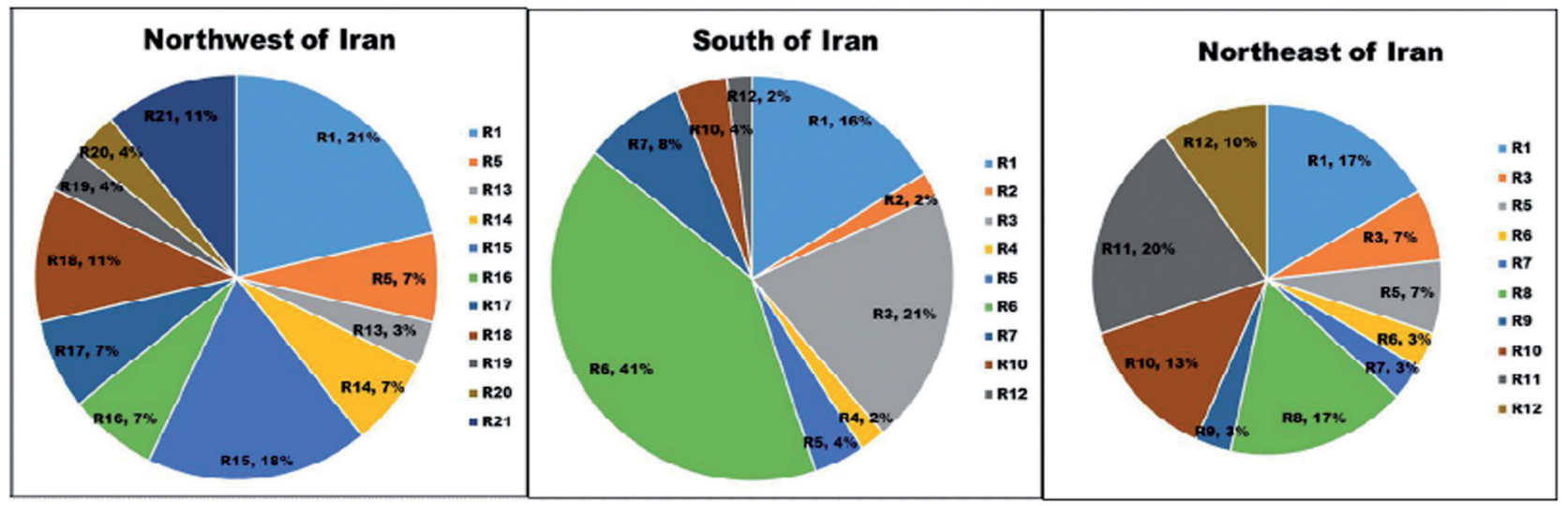

Fig. 1

RFLP pattern of 10 restrictotypes of coat protein gene of GFLV isolates

(a) RFLP pattern of 10 restrictotypes of coat protein gene of GFLV isolates from the northeast of Iran derived using TaqI endonuclease. M: Molecular weight marker $1 \mathrm{~kb}$ DNA Ladder. DNA size of the RFLP fragments is shown in Table 3. (b) Rates (\%) of prevalence of GFLV restrictotypes from the three different geographical regions in Iran. 
Table 3. Prevalence of RFLP pattern in geographical region of Iran

\begin{tabular}{llccc}
\hline Restrictotype & Fragment sizes & Northeast & South & Northwest \\
\hline R1 & 1515 & 5 & 8 & 6 \\
R2 & 1400,100 & - & 1 & - \\
R3 & 1220,295 & 2 & 10 & - \\
R4 & $1100,220,195$ & - & 1 & - \\
R5 & 1030,485 & 2 & 2 & 2 \\
R6 & 900,615 & 1 & 20 & - \\
R7 & $848,553,114$ & 1 & 4 & - \\
R8 & $848,502,114,51$ & 5 & - & - \\
R9 & $729,585,201$ & 1 & - & - \\
R10 & $540,434,415,75$, & 4 & 2 & - \\
& 51 & & & \\
R11 & $553,528,320,114$ & 6 & - & - \\
R12 & $553,552,434$ & 3 & 1 & - \\
R13 & $836,377,273,29$ & - & - & 1 \\
R14 & $564,490,411,37$, & - & - & 2 \\
& 13 & & & \\
R15 & $585,524,377,29$ & - & - & 5 \\
R16 & $786,377,323,29$ & - & - & 2 \\
R17 & $585,406,323,201$ & - & - & 2 \\
R18 & $786,323,266,111$, & - & - & 3 \\
& 29 & & & \\
R19 & $765,377,323,29$, & - & - & 1 \\
& 21 & & & \\
R20 & $585,377,323,201$, & - & - & 1 \\
R21 & 29 & & & \\
& $585,411,175,165$, & - & - & 3 \\
\hline Total & 150,29 & & & \\
\hline
\end{tabular}

clade (Fig. 2). Isolates from France, Italy, Spain, Germany, Austria, Slovenia, Czech Republic, Hungary, Poland, USA, Canada, Chile, Brazil, South Africa, Tunisia, China and Iran were arranged in GFLV-G clade (Fig. 2).

Analysis showed that GFLV populations in GFLV-Ir clade could be further divided into two distinct sub-clades, GFLVIr.nw and GFLV-Ir.nes, corresponding to their geographical origin (Fig. 2). The GFLV-Ir.nw subclade comprised GFLV isolates from the northwest of Iran whereas the GFLV- Ir.nes subclade comprised isolates from the northeast and south of Iran.

The mean sequence distance among isolates in GFLV-G and GFLV-Ir clades was $0.124 \pm 0.036$ and $0.102 \pm 0.025$, respectively. The mean sequence distance between these two groups was $0.129 \pm 0.035$.

Classification of GFLV isolates into genotype groups was performed by pairwise identity score analysis. In this regard, we compared the proportions of CP sequence pairs with similar identity scores (64980 pairwise scores for 361 isolates) at $1 \%$ identity intervals using SDT program. These values concentrated with a clear peak at the score of $88.4 \%$; hence, we proposed the threshold at a greater value, $89 \%$, as the baseline for genotype differentiation of GFLV isolates. Based on these criteria, $361 \mathrm{GFLV}$ isolates were assigned into 37 genotype groups. Members of GFLV-G and GFLV-Ir clades were divided into 31 and 6 different genotype groups, respectively. The number of isolates in each genotype group and distribution of genotypes in different countries are shown in Fig. 3 and Table 1.

Genetic differentiation between geographical subpopulations of GFLV

To verify that the two divergent clades in the phylogentic tree represent distinct subpopulations of GFLV, independent tests of population differentiation were performed (Table 4). All the statistic tests including $\mathrm{K}_{\mathrm{ST}}, \mathrm{Z}^{*}$ and Snn were significant, suggesting that GFLV-G and GFLV-Ir groups represented two diverse subpopulations within the GFLV population structure (Table 4 ).

Moreover, the three statistical tests of population differentiation indicated that GFLV populations from Iran, Europe, North America, South America and Africa were distinct as shown by the significant low values of $\mathrm{K}_{\mathrm{ST}}$ and $\mathrm{Z}^{\star}$ statistics and high value of Snn statistic $(P<0.05$; Table 4$)$. Next, we used coefficient of gene differentiation, $\mathrm{F}_{\mathrm{ST}}$, to measure the extent of genetic differentiation between geographical populations. The highest $\mathrm{F}_{\mathrm{ST}}$ value (0.188) was between GFLV populations from Iran and Africa, suggesting that most of the genetic variation was between these populations. The lowest $\mathrm{F}_{\mathrm{ST}}(0.04)$, however, was found between GFLV populations from Europe and North America.

When differentiation among geographically separated isolates of Iran was examined, the related Snn values were significantly high (mostly near 1.000). Accordingly, the geographical subpopulations of GFLV from Iran (belonging to GFLV-Ir group), could be differentiated from each other (Table 4). This finding was also supported by $\mathrm{K}_{\mathrm{ST}}$ and $\mathrm{Z}^{*}$ tests showing the significant differences between these subpopulations $(P<0.05)$.

\section{Population characteristics and patterns of intraspecific} polymorphism for GFLV

The nucleotide diversity $(\pi)$ and number of parsimonious sites (S) were 0.0531 and 851 for the GFLV-Ir subpopulation and 0.0423 and 200 for the GFLV-G subpopulation, respectively (Table 5 ).

Furthermore, the ratio of nonsynonymous to synonymous nucleotide diversity ( $\mathrm{dN} / \mathrm{dS}$ ratio) was less than 1 for all of the subpopulations. The $\mathrm{dN} / \mathrm{dS}$ ratio of GFLV-G and GFLV-Ir clades were calculated to be 0.60 and 0.73 , respectively. The largest ratios were obtained for GFLV from Iran and South America (0.785 and 0.767 , respectively) and smallest ratio 


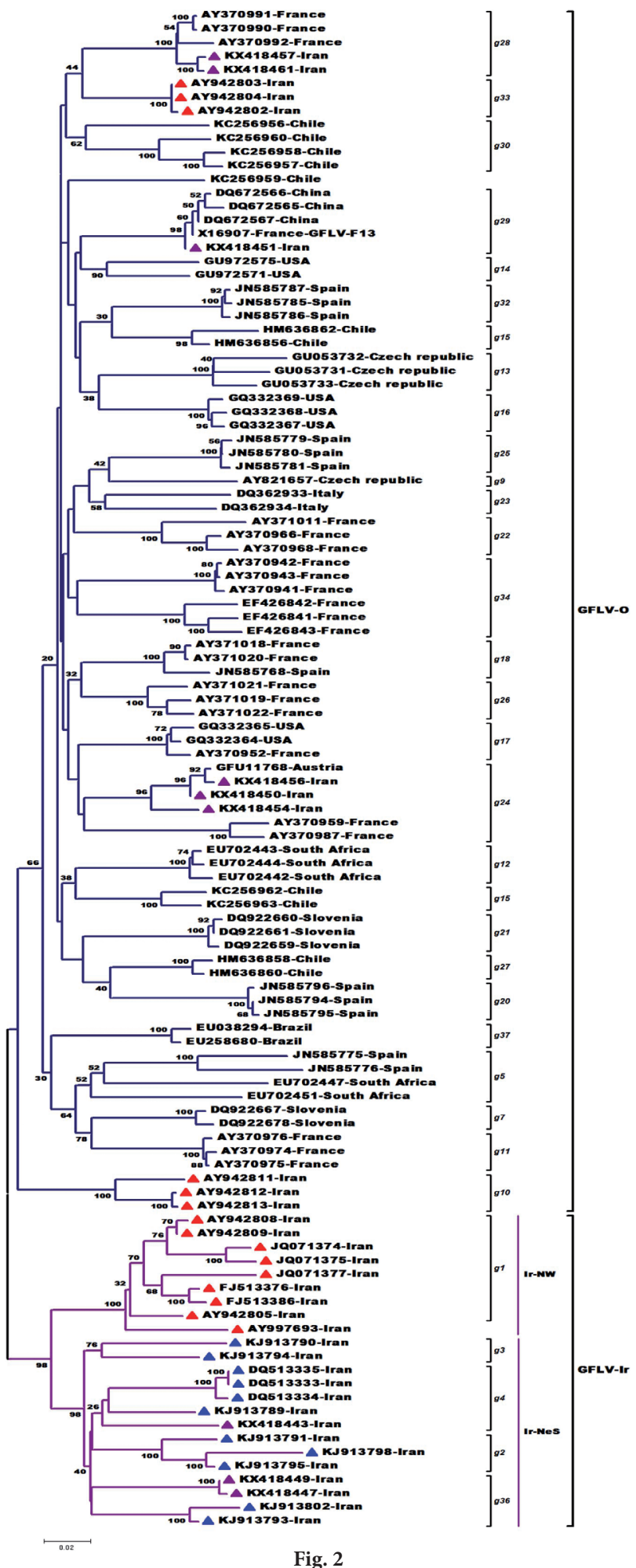

Phylogenetic tree based on the GFLV coat protein nucleotide sequence

Tree represents relations of the GFLV genotypic groups coupled with color-based plot for demonstration of nucleotide sequence identity of GFLV coat protein in Iranian and world isolates available in the GenBank. The GFLV population segregates into two divergent subpopulations designated as GFLV-G and GFLV-Ir. Evolutionary analysis was conducted using MEGA5. The percentage of replicate trees in which the associated taxa clustered together in the bootstrap test (1000 replicates) is shown next to the branches. GenBank Acc. Nos. of the isolates are listed in Table 1. To present the geographical origins of the Iranian isolates, the northwest, south and northeast isolates are shown in red, blue and purple colors. 
(a)

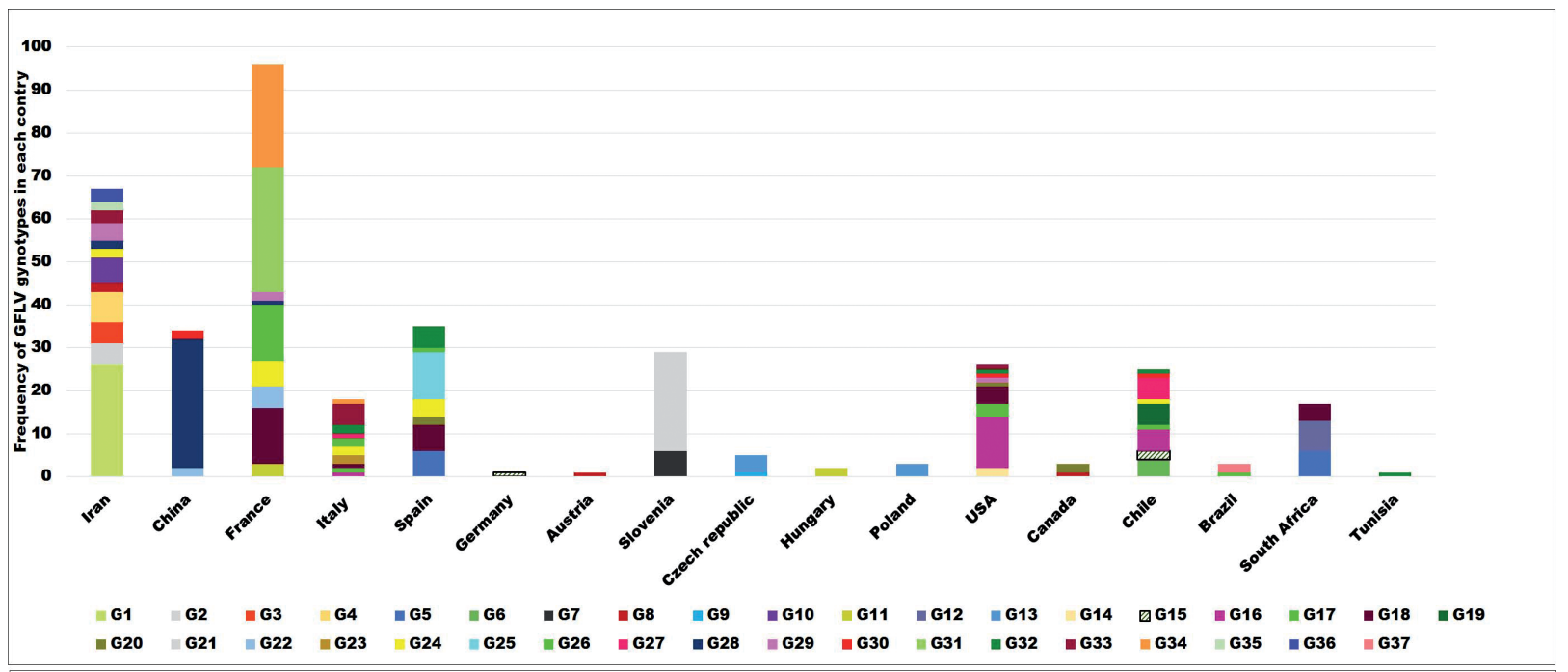

(b)

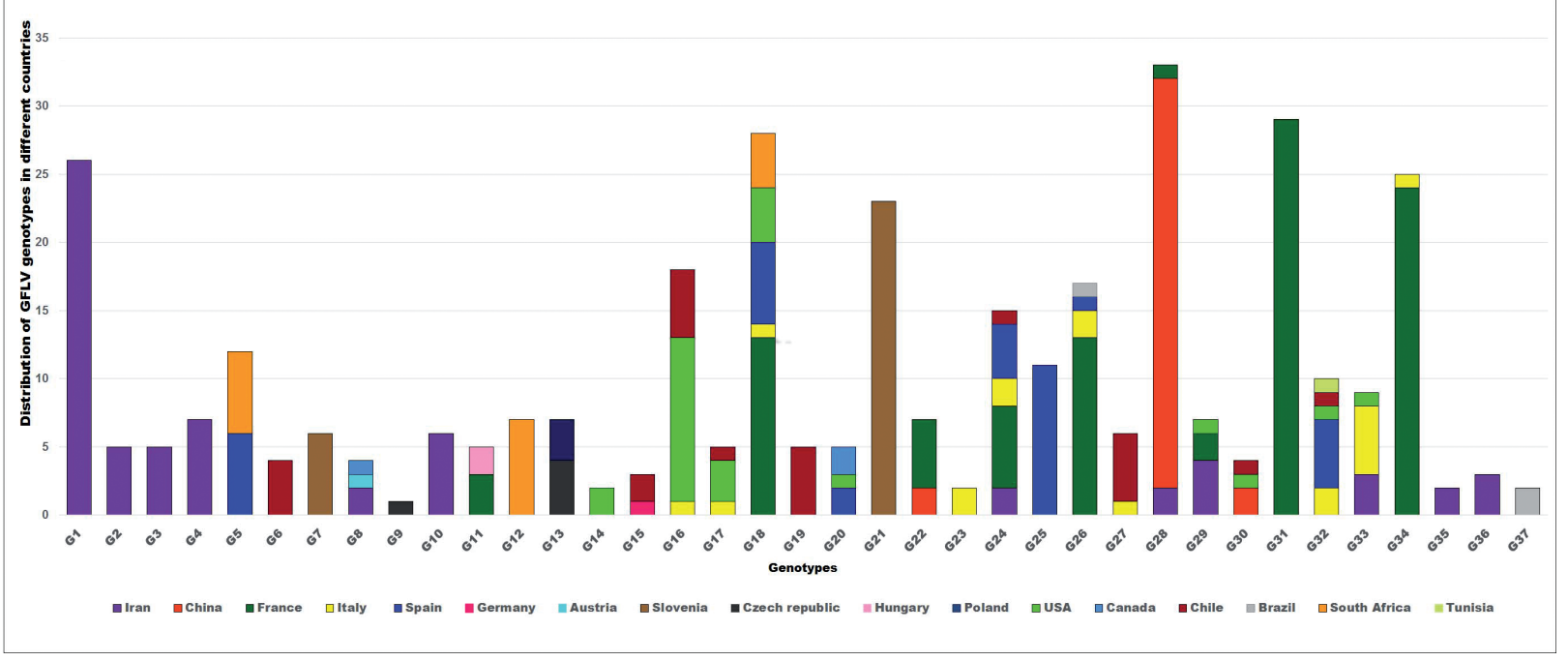

Fig. 3

Graphical distribution of GFLV genotypes

(a) Graphical representation of the distribution of GFLV genotypes from various countries. Y axis shows rates (\%) of sequence variants; each frame represents one sequence variant. Color code for GFLV genotypes is in the bottom. (b) Worldwide prevalence of GFLV genotypes. Color code of countries is at the bottom.

Table 4. Results of genetic differentiation analysis for subpopulation of GFLV

\begin{tabular}{|c|c|c|c|c|c|c|c|c|}
\hline Population & $\mathbf{K s}^{*}$ & Kst $^{*}$ & $\begin{array}{c}\text { Ks }^{*}, \mathrm{Kst}^{*}, \\
\text { P-value }\end{array}$ & $\mathrm{Z}^{*}$ & P-value & Snn & P-value & FST \\
\hline GFLV-G/GFLV-Ir & 4.027 & 0.012 & $0.000^{* * *}$ & 10.377 & $0.000^{* * *}$ & 0.974 & $0.000^{* * *}$ & 0.060 \\
\hline Europe $^{*}$ N. America & 3.753 & 0.008 & $0.000^{* * *}$ & 9.576 & $0.000^{* * *}$ & 0.944 & $0.000^{* * *}$ & 0.040 \\
\hline Europe $^{*}$ S. America & 4.042 & 0.008 & $0.000^{* * *}$ & 9.540 & $0.000^{* * *}$ & 0.957 & $0.000^{* * *}$ & 0.078 \\
\hline Europe $^{*}$ Africa & 3.963 & 0.007 & $0.000^{* * *}$ & 9.427 & $0.000^{* * *}$ & 0.988 & $0.000^{* * *}$ & 0.084 \\
\hline Europe $^{\star}$ Iran & 4.184 & 0.025 & $0.000^{* * *}$ & 9.789 & $0.000^{\star * *}$ & 0.971 & $0.000^{* * *}$ & 0.109 \\
\hline N. America* S. America & 3.953 & 0.021 & $0.001^{* *}$ & 6.528 & $0.001^{*}$ & 0.882 & $0.000^{* * *}$ & 0.061 \\
\hline N. America* Africa & 3.561 & 0.031 & $0.000^{\star * *}$ & 5.992 & $0.000^{* * *}$ & 0.980 & $0.000^{* * *}$ & 0.070 \\
\hline N. America* Iran & 4.276 & 0.026 & $0.000^{* * *}$ & 7.733 & $0.000^{* * *}$ & 0.981 & $0.000^{* * *}$ & 0.099 \\
\hline S. America* Africa & 4.194 & 0.037 & $0.000^{\star * *}$ & 5.674 & $0.000^{* * *}$ & 0.900 & $0.000^{* * *}$ & 0.134 \\
\hline S. America* Iran & 4.832 & 0.015 & $0.000^{* * *}$ & 7.676 & $0.000^{* * *}$ & 0.965 & $0.000^{* * *}$ & 0.074 \\
\hline
\end{tabular}


Table 4 (continued)

\begin{tabular}{|c|c|c|c|c|c|c|c|c|}
\hline Population & $\mathbf{K s}^{*}$ & Kst $^{*}$ & $\begin{array}{c}\mathrm{Ks}^{\star}, \mathrm{Kst}^{\star}, \\
\text { P-value }\end{array}$ & $\mathbf{Z}^{*}$ & P-value & Snn & P-value & FST \\
\hline Africa* Iran & 5.305 & 0.025 & $0.000^{* * *}$ & 7.387 & $0.000^{* * *}$ & 1.000 & $0.000^{* * *}$ & 0.188 \\
\hline Nw. $\operatorname{Iran}^{\star}$ Ne. Iran & 5.458 & 0.047 & $0.000^{* * *}$ & 6.675 & $0.000^{* * *}$ & 0.993 & $0.000^{* * *}$ & 0.221 \\
\hline Nw. Iran* Sw. Iran & 5.833 & 0.013 & $0.008^{* *}$ & 6.431 & $0.025^{*}$ & 0.933 & $0.000^{* * *}$ & 0.059 \\
\hline Ne. Iran* Sw. Iran & 5.350 & 0.041 & $0.001^{* *}$ & 5.278 & $0.000^{* * *}$ & 0.837 & $0.004^{* *}$ & 0.160 \\
\hline
\end{tabular}

Ks: synonymous nucleotide divergence; Kst*: Sequence-based genetic differentiation statistics described by Hudson et al., 1992 ; $Z^{\star}$ : logarithm of the $\mathrm{Z}$ statistics and $\mathrm{Z}$ results from ranking distances between all pairs of sequences where the average ranks for those from within two locations are summed and the sum is weighted (11); Snn: the frequency with which the nearest neighbors of sequences are found in the same locality (13); $\mathrm{F}_{\mathrm{ST}}$ : coefficient of gene differentiation or fixation index, which measures inter-population diversity $(11){ }^{*}: 0.01<\mathrm{P}<0.05 ;{ }^{* *}, 0.001<\mathrm{P}<0.01 ;{ }^{* *}$ : $\mathrm{P}<0.001$.

was found in African population of GFLV (Table 5). Also, the $\mathrm{dN} / \mathrm{dS}$ ratio for GFLV of southern Iran was higher than that of the northeast (Table 5).

We also evaluated the distribution of nucleotide polymorphisms in the genome using Tajima's D and Fu and Li's D and $F$ test (Table 6). Tajima's $D$ values were negative for
GFLV-G and GFLV-Ir populations and also for geographically different populations (Table 6). However, the values of Fu and Li's D and F statistics were positive for GFLV-G and GFLV-Ir populations.

Also, the values of Tajima's D and Fu and Li's D and F statistic tests were positive for GFLV isolates of the northwest

Table 5. Genetic polymorphism in the coat protein gene from different subpopulation of grapevine fanleaf virus

\begin{tabular}{|c|c|c|c|c|c|c|c|c|c|c|}
\hline & No. seq. & $S$ & $\eta$ & $\mathbf{k}$ & $\pi$ & SS & NS & dS & $\mathrm{dN}$ & $\mathrm{dN} / \mathrm{dS}$ \\
\hline GFLV-G & 296 & 200 & 600 & 84.696 & 0.0423 & 45.221 & 146.779 & 0.92195 & 0.55429 & 0.601 \\
\hline GFLV-Ir & 65 & 851 & 2303 & 452.400 & 0.0531 & 199.400 & 649.601 & 1.17209 & 0.86291 & 0.736 \\
\hline Asia & 9 & 233 & 236 & 117.66 & 0.0312 & 67.917 & 241.083 & 0.48169 & 0.54193 & 1.125 \\
\hline Europe & 174 & 259 & 745 & 91.453 & 0.0353 & 59.821 & 195.179 & 0.80706 & 0.40000 & 0.496 \\
\hline n. America & 39 & 202 & 449 & 77.792 & 0.0385 & 47.167 & 150.833 & 0.77186 & 0.48327 & 0.626 \\
\hline s. America & 30 & 312 & 736 & 151.61 & 0.0486 & 71.414 & 240.586 & 0.94701 & 0.74379 & 0.785 \\
\hline Africa & 18 & 462 & 569 & 132.17 & 0.0231 & 132.396 & 437.604 & 0.52990 & 0.21520 & 0.406 \\
\hline Iran-overall & 91 & 759 & 2230 & 446.315 & 0.0588 & 178.352 & 577.647 & 1.41318 & 1.08338 & 0.767 \\
\hline Nw. Iran & 50 & 756 & 1745 & 459.91 & 0.0605 & 180.137 & 575.864 & 1.30820 & 1.21561 & 0.929 \\
\hline Ne. Iran & 22 & 1229 & 2048 & 429.55 & 0.0334 & 294.494 & 986.507 & 0.72080 & 0.37768 & 0.524 \\
\hline S. Iran & 19 & 979 & 2403 & 670.22 & 0.0684 & 221.750 & 756.250 & 1.83153 & 1.83376 & 1.001 \\
\hline
\end{tabular}

S: number of polymorphic sites; $\eta$ (eta): total number of mutations; $\mathrm{k}$ : average number of nucleotide differences between sequences; $\pi$ : nucleotide diversity; SS: total number of synonymous sites analyzed; NS: total number of non-synonymous sites analyzed; dS: synonymous nucleotide diversity; dN: non-synonymous nucleotide diversity.

Table 6. Summary of parameter estimates and test statistics examined for demographic trends in GFLV populations

\begin{tabular}{lcccc}
\hline Geographic group & Tajima's Da & Fu \& Li's D & Fu \& Li's F* & Hd \\
\hline GFLV-G & -0.252 & $3.601^{* *}$ & $1.761^{*}$ & 0.998 \\
GFLV-IR & -0.242 & 1.202 & 0.737 & 0.998 \\
Europe & -0.793 & 2.154 & 0.740 & 0.998 \\
n. America & -1.069 & 0.471 & -0.085 & 0.981 \\
s. America & -0.743 & 0.092 & -0.221 & 0.0331 \\
Africa & -1.004 & 0.739 & 0.277 & 0.0385 \\
Iran & 0.028 & 2.013 & 1.385 & 0.992 \\
Nw. Iran & 0.660 & $2.147^{* *}$ & $1.889^{*}$ & 0.997 \\
Ne. Iran & -0.762 & -0.911 & -1.018 & 0.0486 \\
Sw. Iran & -1.059 & 0.190 & -0.139 & 0.0588 \\
\hline
\end{tabular}

Hd: haplotype diversity; $\pi$ : nucleotide diversity per site. 
was found in African population of GFLV (Table 5). Also, the $\mathrm{dN} / \mathrm{dS}$ ratio for GFLV s of southern Iran was higher than that of the northeast (Table 5).

We also evaluated the distribution of nucleotide polymorphisms in the genome using Tajima's D and Fu and Li's D and $\mathrm{F}$ test (Table 6). Tajima's $\mathrm{D}$ values were negative for GFLV-G and GFLV-Ir populations and also for geographically different populations (Table 6). However, the values of $\mathrm{Fu}$ and Li's D and F statistics were positive for GFLV-G and GFLV-Ir populations.

Also, the values of Tajima's D and Fu and Li's D and F statistic tests were positive for GFLV isolates of the northwest of Iran, whereas they were negative for isolates of the south and northeast (Table 6).

The amount of haplotype diversity and nucleotide diversity of GFLV populations were also compared. Both values were high for all GFLV subpopulations ranging from 0.992 to 1.000 for the haplotype diversity and from 0.0231 to 0.0684 for the nucleotide diversity (Table 6). The highest and the lowest values of the nucleotide diversity were obtained for GFLV populations from the south and the north-east of Iran, respectively (Table 6).

\section{Discussion}

In the present study, the heterogeneous nature of the genome of GFLV isolates originating from 17 countries (including isolates from three regions of Iran) was studied by comparing their CP gene sequences.

To this purpose, 41 new Iranian GFLV-CP gene sequences obtained in this study together with those retrieved from GenBank were used to gain an insight into the population dynamics and genetic diversity of GFLV strains in the world.

The RFLP data using TaqI restriction enzyme indicated that GFLV populations in Iran were organized in 21 restrictotypes. In many cases more than one GFLV restrictotype was observed in represented population structure. Similarly, mixed infections with several haplotypes in GFLV populations have been previously reported from France, USA and Tunisia (Fattouch et al., 2005; Naraghi-Arani et al., 2001; Vigne et al., 2009).

Our RFLP analysis showed that restrictotypes R1, R8 and R11 in the south of Iran, and R1, R3, R6 in the northeast of Iran were the most common mutants with 80 and $53 \%$ of incidence, respectively. The Iranian GFLV isolates analyzed here were obtained across a wide and diverse geographical area, and were associated with variable GFLV symptoms. Considerable variability in RFLP data reflects the presence of different mutant genomes selected under the pressure of host variety and environmental factors. As considered previously (Naraghi-Arani et al., 2001), the existence of subpopulations within the GFLV population structure sug- gests the organization of variants in natural populations of the virus in the form of quasispecies.

Coat protein gene analysis showed that GFLV isolates are genetically variable and could be divided into two major phylogenetic clades and 37 genotype groups. The genetic variation in the CP gene of GFLV enhances the fitness and adaptation of a virus when it shifted to a new ecological niche or selective constraint (Garcia-Arenal et al., 2001; Moya et al., 2000).

The pairwise sequence identity score of $89 \%$ was defined as the threshold for the genotype grouping of GFLV isolates with high confidence. Based on this threshold, isolates within the GFLV-G clade were divided into 31 genotypes and those of GFLV-Ir were divided into 6 genotypes. Such scoring approaches have been previously used for genotyping of mastreviruses (Muhire et al., 2013), potato virus S (Salari et al., 2011) and potato virus $M$ (Tabasinejad et al., 2014).

According to our findings, the genotype groups GFLV-g18 $(\mathrm{n}=27)$, GFLV-g21 ( $\mathrm{n}=23)$, GFLV-g28 $(\mathrm{n}=33)$, GFLV-g31 $(\mathrm{n}=29)$ and GFLV-g34 $(\mathrm{n}=25)$ were the most common genotypes in GFLV-G clade, whereas GFLV-g1 $(\mathrm{n}=25)$ was the prevalent genotype in GFLV-Ir clade. Among the 17 countries, Iran had the highest number of genotypes (12 genotypes) followed by Italy (11 genotypes), USA (10 genotypes), Chile (9 genotypes), France ( 8 genotypes) and Spain (7 genotypes).

We showed that the sequence variation along the $\mathrm{CP}$ gene of GFLV isolates is controlled by purifying (negative) selection pressure. This could be explained by functional importance of the GFLV CP gene. CP-based phylogenetic analysis showed the polyphyletic origin of the GFLV isolates from Iran. This finding is not consistent with a previous report describing Iranian GFLV populations as a monophyletic lineage based on the analysis of movement protein (MP) gene (Bashir and Melcher, 2012). Hence, it may conclude that incorporation of MP gene sequence data into the CP dataset provides a better insight in the diversity of GFLV populations. However, the MP sequence data are not available for most of the GFLV isolates across the world that could affect the reliability of statistical analysis.

Results of this study suggest that Iranian GFLV isolates originated from different ancestors; or they have been exposed to different environmental conditions in their geographical regions driving the genomes to undergo independent evolutions. On the other hand, generation of several lineages for the GFLV virus population may have resulted from founder effects, meaning that different GFLV genotypes had been introduced into the vineyards. Nonetheless, the diversification rate has varied for different lineages and some genotypes have generated more progenies than others. Similar conclusion has been obtained in the analysis of GFLV populations from France, Germany, Italy and the USA (Bashir and Melcher, 2012). 
In the depicted phylogenetic tree, the relatively long terminal branches of the GFLV isolates from northeast of Iran (KJ913794, KJ913790, KJ913798, KJ913789) may be due to the accumulation of mutants along the genome over a long time. It appears that the GFLV subpopulation from northeast of Iran has not diversified recently because each isolate is resolved on independent deep-branching lineage. This is in agreement with the largest number of segregating sites (1229), low rates of diversification (0.0334), high level of haplotype diversity (0.994) and low selection pressure (0.524) found in this subpopulation.

Although the majority of GFLV population from northwest of Iran, including four complete RNA2 segment (JQ071374, JQ071374, JQ071376, JQ071377) (Nourinejhad Zarghani et al., 2013), were grouped into the GFLV-Ir clade, they were resolved in subclades distinct from those of other Iranian isolates. This finding suggests that these isolates carry similar mutations. The CP gene of GFLV population from northwest of Iran (placed in the GFLV-Ir clade) revealed high polymorphism rate that might be due to the exertion of high selection pressure. This assumption was supported by significant positive values of the neutrality test statistics for isolates in this population (rejection of the null hypothesis of neutrality).

All examined subpopulations in GFLV population structure could be differentiated from each other based on the significant values $(P$-values $<0.05)$ of the test statistics Kst ${ }^{*}$, $\mathrm{Z}^{\star}$, Snn and $\mathrm{F}_{\mathrm{ST}}$. Moreover, all populations in the GFLV-G clade were differentiated from the Iranian GFLV populations in the GFLV-Ir clade using test statistic Snn supported by $P$-value less than 0.05 . Similarly, Iranian isolates in GFLVIr clade were differentiated from European, American or African populations.

GFLV have been proposed to be originated from ancient Persia (Vuittenez, 1970). This argues with that long-term divergence of the virus populations in Iran may be associated with founder effects.

The significantly positive values of Tajima's D and Fu and Li's $\mathrm{D}^{\star}$ and $\mathrm{F}^{*}$ statistics obtained for the GFLV population from the northwest of Iran, evidenced the occurrence of balancing selection or sudden population contraction in this region. These findings also provide evidence for a recent bottleneck or overdominant selection in this population.

Contrary to the above, the negative Tajima's D and Fu and Li's D and F-values suggest low frequency of polymorphism that is associated with background selection or population growth (Fu and Li, 1993; Tajima, 1989). For the majority of geographical groups the values of Tajima's D and Fu and Li's D and $\mathrm{F}^{\star}$ tests were negative, revealing the occurrence of the expansion in GFLV populations after a recent bottleneck (Bashir and Melcher, 2012). Thus, these tests provide an evidence for purifying selection in the CP gene that allows the population size to grow.
In conclusion, we showed quasispecies nature of the Iranian GFLV populations consisting of 21 restrictotypes and 12 genotypes. Differentiation among the geographical populations of Iranian GFLV isolates was the major finding of this study. The polyphyletic status of the Iranian population appeared to arise from the long-term presence of the virus in the region, founder effects or recombination. Also, the transfer of the infected grapevine material and environmental factors may have played a role in the shaping of GFLV population structure in Iran.

\section{References}

Andret-Link P, Laporte C, Valat L, Ritzenthaler C, Demangeat G, Vigne E, Laval V, Pfeiffer P, Stussi-Garaud C, Fuchs M (2004): Grapevine fanleaf virus: still a major threat to the grapevine industry. J. Plant Pathol. 86, 183-195.

Bashir NS, Nikkhah S, Hajizadeh M (2007a): Distinct phylogenetic positions of Grapevine fanleaf virus isolates from Iran based on the movement protein gene. J. Gen. Plant Pathol. 73, 209-215. https://doi.org/10.1007/s10327$\underline{007-0012-1}$

Bashir NS, Zarghani SN, Hejazi MS (2007b): Diversity of grapevine fanleaf virus isolates from Iran. Virus Res. 128, 144-148. https://doi.org/10.1016/j.virusres.2007.04.013

Bashir NS, Pashaei A, Doulati-Baneh H (2011): Characterization of the full length coat protein gene of Iranian Grapevine fanleaf virus isolates genetic variation and phylogenetic analysis. Iran. J. Biotech. 9, 213-221.

Bashir N, Melcher U (2012): Population genetic analysis of grapevine fanleaf virus. Arch. Virol. 157, 1919-1929. https:// doi.org/10.1007/s00705-012-1381-0

Converse RH, Martin RP (1990): ELISA methods for plant viruses. In Hampton R, Ball E, De Boer S (Eds): Serological Methods for Detection and Identification of Viral and Bacterial Plant Pathogens. A Laboratory Manual. APS Press, USA, pp. 179-196.

Fattouch S, Acheche H, Mhirsi S, Mellouli L, Bejar S, Marrakchi M, Marzouki N (2005): RT-PCR-RFLP for genetic diversity analysis of Tunisian grapevine fanleaf virus isolates in their natural host plants. J. Virol. Methods 127, 126-132. https://doi.org/10.1016/j.jviromet.2005.03.008

Fu YX, Li WH (1993): Statistical tests of neutrality of mutations. Genetics 133, 693-709.

Garcia-Arenal F, Fraile A, Malpica JM. (2001): Variability and genetic structure of plant virus populations. Ann. Rev. Phytopathol. 39, 157-186. https://doi.org/10.1146/annurev.phyto.39.1.157

Gibbs A, Mackenzie A (1997): A primer pair for amplifying part of the genome of all potyvirids by RT-PCR. J. Virol. Methods 63, 9-16. https://doi.org/10.1016/S0166-0934(96)02103-9

Hudson RR, Boos DD, Kaplan NL (1992a): A statistical test for detecting population subdivision. Mol. Biol. Evol. 9, 138-151. 
Hudson RR, Slatkin M, Maddison WP (1992b): Estimation of levels of gene flow from DNA sequence data. Genetics $132,583-589$.

Hudson RR (2000): A new statistic for detecting genetic differentiation. Genetics 155, 2011-2014.

Izadpanah K, Zaki-Aghl M, Zhang YP, Daubert SD, Rowhani A (2003a): Bermuda grass as a potential reservoir host for grapevine fanleaf virus. Plant. Dis. 87, 1179-1182. https://doi.org/10.1094/PDIS.2003.87.10.1179

Izadpanah K, Zaki-Aghl M, Rowhani A (2003b): Non-vitis hosts of grapevine fanleaf virus and their possible epidemiological significance. Proceedings of the 14th ICVG Conference. Locorotondo, Italy.

Libardo P, Rozas J (2009): DnaSP v5: a software for comprehensive analysis of DNA polymorphism data. Bioinformatics 25, 1451-1452. https://doi.org/10.1093/bioinformatics/ btp187

Moya A, Elena SF, Bracho A, Miralles R, Barrio E (2000): The evolution of RNA viruses: a population genetics view. PNAS 97, 6967-6973. https://doi.org/10.1073/pnas.97.13.6967

Muhire B, Martin DP, Brown JK, Navas-Castillo J, Moriones E, Zerbini FM, Rivera-Bustamante R, Malathi VG, Briddon RW, Varsani A (2013): A genome-wide pairwise-identitybased proposal for the classification of viruses in the genus Mastrevirus (family Geminiviridae). Arch. Virol. 158, 1411-1424. https://doi.org/10.1007/s00705-012-1601-7

Naraghi-Arani P, Daubert S, Rowhani A (2001): Quasispecies nature of the genome of grapevine fanleaf virus. J. Gen. Virol. 82, 1791-1795. https://doi.org/10.1099/0022-1317 $\underline{-82-7-1791}$

Nolasco G, de Sequeira OA (1993): Genome diversity of field isolates of grapevine fanleaf virus (GFLV) analyzed by single stranded conformation (SSCP) and restriction fragment length (RFLP) polymorphisms. 11th Meeting of the International Council for the Study of Viruses and Virus-like Diseases of the Grapevine, Montreux, Switzerland.

Nourinejhad-Zarghani S, Shams-Bakhsh M, Sokhandan-Bashir N, Wetzel T (2013): Molecular characterization of whole genomic RNA2 from Iranian isolates of grapevine fanleaf virus. J. Phytopathol. 161, 419-425. https://doi. org/10.1111/jph.12089

Pinck L, Fuchs M, Pinck M, Ravelonandro M, Walter B (1988): A satellite RNA in grapevine fanleaf virus strain F13. J. Gen. Virol. 69, 233-239. https://doi.org/10.1099/00221317-69-1-233

Pourrahim R, Farzadfar S, Golnaraghi AR, Ahoonmanesh A (2007): Partial molecular characterization of some grapevine fanleaf virus isolates from North-east of Iran. J. Phytopathol. 155, 754-757. https://doi.org/10.1111/j.14390434.2007.01299.x
Salari K, Massumi H, Heydarnejad J, Hosseini-pour A, Varsani A (2011): Analysis of Iranian potato virus $S$ isolates. Virus Genes 43, 281-288. https://doi.org/10.1007/s11262-011 -0619-3

Sanfacon H, Iwanami T, Karasev AV, Van der Vlugt R, Wellink J, Wetzel T, Yoshikawa N (2012): Secoviridae In King AMQ, Adams MJ, Carstens EB, Lefkowitz EJ (Eds): Virus taxonomy. Ninth report of the ICTV. Elsevier, Academic Press, London, pp. 881-899.

Schneider WL, Roossinck MJ (2000): Evolutionarily related Sindbislike plant viruses maintain different levels of population diversity in a common host. J. Virol. 74, 3130-3134. https://doi.org/10.1128/JVI.74.7.3130-3134.2000

Serghini MA, Fuchs M, Pinck M, Reinbolt J, Walter B, Pinck L (1990): RNA2 of grapevine fanleaf virus: sequence analysis and coat protein cistron location. J. Gen. Virol. 71, 1433-1441. https://doi.org/10.1099/0022-1317-71-7-1433

Tabasinejad F, Jafarpour B, Zakiaghl M, Siampour M, Rowhani H, Mehrvar M (2014): Genetic structure and molecular variability in potato virus M populations. Arch. Virol. 159, 2081-2090. https://doi.org/10.1007/s00705-014-2037-z

Tajima F (1989): Statistical method for testing the neutral mutation hypothesis by DNA polymorphism. Genetics 123 , 585-595.

Tamura K, Peterson D, Peterson N, Stecher G, Nei M, Kumar S (2011): MEGA5: molecular evolutionary genetics analysis using Maximum Likelihood, Evolutionary Distance, and Maximum Parsimony methods. Mol. Biol. Evol. 28, 2731-2739. https://doi.org/10.1093/molbev/msr121

Tsompana M, Abad J, Purugganan M, Moyer JW (2005): The molecular population genetics of the tomato spotted wilt virus (TSWV) genome. Mol. Ecol. 14, 53-66. https://doi. org/10.1111/j.1365-294X.2004.02392.X

Vigne E, Marmonier A, Komar V, Lemaire O, Fuchs M (2009): Genetic structure and variability of virus populations in crossprotected grapevines superinfected by grapevine fanleaf virus. Virus Res. 144, 154-162. https://doi. org/10.1016/j.virusres.2009.04.018

Vigne E, Gottula J, Schmitt-Keichinger C, Komar V, Ackerer L, Belval L, Rakotomalala L, Lemaire O, Ritzenthaler C, Fuchs M (2013): A strain-specific segment of the RNAdependent RNA polymerase of grapevine fanleaf virus determines symptoms in Nicotiana species. J. Gen. Virol. 94, 2803-2813. https://doi.org/10.1099/vir.0.057646-0

Vuittenez A (1970): Fanleaf of grapevine. In Frazier NW (Eds): Virus Diseases of Small Fruits and Grapevine. Berkeley, University of California, pp. 217-228.

Zaki-Aghl M, Izadpanah K (2003): Serological and molecular identification of grapevine fanleaf virus in Iran. Iran. J. Plant. Pathol. 39, 161-171. 